Research Article

\title{
Study on Repaired Earthquake-Damaged Bridge Piers under Seismic Load
}

\author{
Jun Deng, Tonghua Liu, Weizhi Xie, and Wei Lu \\ School of Civil and Transportation Engineering, Guangdong University of Technology, Guangzhou 510006, China \\ Correspondence should be addressed to Jun Deng; jdeng@gdut.edu.cn
}

Received 8 June 2015; Revised 1 October 2015; Accepted 13 October 2015

Academic Editor: Francisco J. Molina

Copyright (C) 2015 Jun Deng et al. This is an open access article distributed under the Creative Commons Attribution License, which permits unrestricted use, distribution, and reproduction in any medium, provided the original work is properly cited.

The concrete bridge pier damaged during earthquakes need be repaired to meet the design standards. Steel tube as a traditional material or FRP as a novel material has become popular to repair the damaged reinforced concrete (RC) bridge piers. In this paper, experimental and finite element (FE) studies are employed to analyze the confinement effectiveness of the different repair materials. The FE method was used to calculate the hysteretic behavior of three predamaged circle RC bridge piers repaired with steel tube, basalt fiber reinforced polymer (BFRP), and carbon fiber reinforced polymer (CFRP), respectively. Meanwhile, the repaired predamaged circle concrete bridge piers were tested by pseudo-static cyclic loading to study the seismic behavior and evaluate the confinement effectiveness of the different repair materials and techniques. The FE analysis and experimental results showed that the repaired piers had similar hysteretic curves with the original specimens and all the three repair techniques can restore the seismic performance of the earthquake-damaged piers. Steel tube jacketing can significantly improve the lateral stiffness and peak load of the damaged pier, while the BFRP and CFRP sheets cannot improve these properties due to their thin thickness.

\section{Introduction}

In recent years, bridge piers all over the world result in different damage after a majority of the devastating earthquakes [1]. Apart from the victims and the direct economic costs associated with the replacement of these damaged bridge piers, the disruption of crucial roads over a large time period created tremendous difficulties in the logistics of getting assistance to the impacted areas, therefore aggravating the initial consequences of the earthquakes [2]. If damaged bridge piers could be repaired and rehabilitated rapidly, it would be both more economical than demolishing and reconstructing the bridges and also extremely important for rescue efforts after an earthquake [3]. Several traditional reinforcement techniques and the latest ones have been applicable to different reinforcement demand for improving the bearing capacity of bridge piers, seismic strengthening, and postearthquake repair, including increasing composites cross section area, near-surface-mounted, external prestressing, steel jacket, and FRP composites exterior spiral and longitudinal rebar repaired with dog bone bars [4]. Increasing composites cross section area and external prestressing are simple and mature in design and construction, while they are easily subjected to other factors such as site environment and cost. The most widely and promisingly used practical techniques for repair of earthquake-damaged RC bridge piers are steel tube jacketing and FRP wrapping. Therefore, it is indispensable to study and compare their reinforcement effects on earthquake-damaged RC bridge piers.

Many scholars had done some research on reinforcement of bridge piers with steel jacketing or FRP wrapping and obtained certain achievements. Chai et al. [5] analyzed six large-scale reinforced concrete piers strengthened with steel jackets. Matsumoto et al. [6] indicated that steel jacketing is the most popular strengthening method for railway RC viaduct columns in Japan. The existing RC column retrofitted with 6 to $12 \mathrm{~mm}$ thick rectangular steel plates was tested and the ductility of steel jacketed member was evaluated. Gu et al. [7] conducted an experimental study on 17 circle concrete columns retrofitted with FRP under seismic load to evaluate the confinement effectiveness of the type and the amount of FRP. Sun et al. [8] reported a rapid repair technique using 
early-strength concrete with high fluidity and CFRP sheets. The experimental and theoretical results show that this technique is rapid and highly effective. Lee et al. [9] indicated that the main reasons for the selection of steel jackets or CFRP lie in their popular use in structural retrofit applications. Furthermore, continuous BFRP newly developed for application in civil infrastructure shows obvious advantages in mechanical and chemical properties and high ratio of performance to cost in comparison to other FRP composites as well as conventional steel materials [10]. Zhang et al. [11] indicated the outstanding characteristics of basalt fiber: high temperature resistance, ablative resistance (materials in high temperature and flame ability to maintain constant quality), good acid-proof and alkaline-proof characteristics, and thermal stability. The mechanical property and cost of BFRP are close to aramid fiber reinforced polymer (AFRP) and glass fiber reinforced polymer (GFRP), but with better physical properties.

Although an increasing amount of research is becoming available on repair techniques of RC bridge piers, comparisons of the seismic behaviors of RC bridge piers repaired with different materials are scarce. Steel tube repair is the most efficient way to increase the strength, ductility, and seismic behavior of the damaged piers. However, steel jacket improving the stiffness of individual piers may induce more force during earthquakes and further damage to other capacity protected components, which makes an analysis of the entire bridge system necessary. In this paper, three smallscale circle RC bridge piers were damaged using pseudo-static loading and then repaired with steel tube, BFRP, and CFRP, respectively. Modeling approaches describing the hysteretic behavior of the piers were investigated by using ANSYS software as well. The experimental and FE studies were employed to compare the seismic behaviors and confinement effectiveness of the three different repaired piers. The failure modes, energy dissipation, and stiffness degradation of the piers were studied and compared.

\section{Experimental Study}

2.1. Original Specimens. In this paper, the dimensions of the specimens were based on the main bridge piers of Yuzixi-1 Bridge in Sichuan Province of China, which was damaged by Wenchuan Earthquake in 2008. Three originally undamaged circle RC bridge pier specimens were designed to present a one-fifth scale of the prototype piers. Furthermore, the diameters and quantity of the steel bars were given according to the equivalent reinforcement ratio as well as arrangement of steel bars in the original piers, as shown in Figure 1. The height of the piers measured from the top of the footing to the application point of the horizontal force was $2000 \mathrm{~mm}$ and the height of the footing was $500 \mathrm{~mm}$. Each specimen was reinforced with 9 longitudinal steel bars of $12 \mathrm{~mm}$ in diameter with a yield strength of $310 \mathrm{MPa}$. The longitudinal steel bars were evenly distributed in a circle with a constant clear cover of $15 \mathrm{~mm}$ which is the minimum requirements for protective layer. In addition, the specimens were reinforced with $6 \mathrm{~mm}$ spiral bars with a yield strength of $210 \mathrm{MPa}$ spaced at $40 \mathrm{~mm}$. The longitudinal reinforcement ratio and stirrup ratio of the

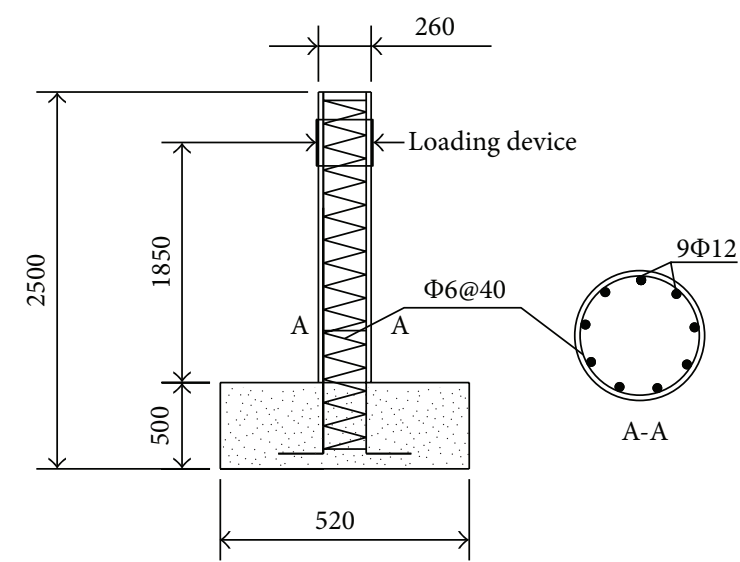

FIGURE 1: Details of the original specimens (unit: mm).

bridge pier were $1.92 \%$ and $1.09 \%$, respectively. The tested cube compressive strength of the concrete in the three specimens was $36.7 \mathrm{MPa}, 40.6 \mathrm{MPa}$, and $40.8 \mathrm{MPa}$, respectively. The difference of the aggregates and other mixtures in the prototype piers and in the specimens can be ignored due to the similar compressive strength of the concrete. The damage mode of the original specimens under the pseudo-static cyclic loading was constraint damage in the flexural plastic hinge region near the bottom of the piers where, subsequent to flexural cracking, cover-concrete crushing and spalling occurred, as shown in Figure 5(a).

2.2. Repair Procedures. To investigate the confinement effectiveness of different materials and techniques, three specimens were repaired by steel tube, CFRP, and BFRP, respectively. The criterion of repair design in the paper referred to the standard of design code for strengthening concrete structure [12]. Specimen A was repaired by jacketing a steel tube with a thickness of $1.7 \mathrm{~mm}$, a diameter of $300 \mathrm{~mm}$, and a length of $2000 \mathrm{~mm}$ according to the actual repaired bridge. The steel tube had a yield strength of $400 \mathrm{MPa}$ and a modulus of elasticity of $200 \mathrm{GPa}$. Specimen B was repaired by wrapping two layers of BFRP sheets. The BFRP sheet had a tensile strength of $2303 \mathrm{MPa}$, a modulus of elasticity of $105 \mathrm{GPa}$, a rupture strain of $1.83 \%$, and a thickness of $0.111 \mathrm{~mm}$ (provided by the manufacturer). Specimen $\mathrm{C}$ was repaired by wrapping two layers of CFRP sheets. The CFRP sheet had a tensile strength of $3400 \mathrm{MPa}$, a modulus of elasticity of $245 \mathrm{GPa}$, a rupture strain of $1.67 \%$, and a thickness of $0.111 \mathrm{~mm}$ (provided by the manufacturer).

The thickness of the steel tube was given according to the equivalent reinforcement ratio of the prototype piers, while the thickness of CFRP and BFRP sheet was given according to the confining effectiveness [13]. A study had shown no significant size effect for FRP wrapped RC columns, despite the fact that the specimens were much smaller than the real columns [14]. All the piers had a circular section with a diameter of $260 \mathrm{~mm}$, except for specimen A-R with a diameter of $300 \mathrm{~mm}$ due to the thickness of the steel tube and the concrete filling. The details of the original specimens and repaired specimens are shown in Table 1. 
TABLE 1: Details of the specimens.

\begin{tabular}{lccc}
\hline Specimen & Diameter $(\mathrm{mm})$ & $f_{c}(\mathrm{MPa})$ & Reinforcement method \\
\hline A & 260 & 36.7 & None \\
A-R & 300 & 36.7 & Steel tube jacketing \\
B & 260 & 40.6 & None \\
B-R & 260 & 40.6 & BFRP wrapping \\
C & 260 & 40.8 & None \\
C-R & 260 & 40.8 & CFRP wrapping \\
\hline
\end{tabular}

TABLE 2: Mix proportions of self-compacting concrete with high fluidity $\left(\mathrm{kg} / \mathrm{m}^{3}\right)$.

\begin{tabular}{cccccc}
\hline Water & Cement & Sand & Aggregate & $\begin{array}{c}\text { Water } \\
\text { reducer }\end{array}$ & $\begin{array}{c}\text { Water- } \\
\text { cement } \\
\text { ratio }\end{array}$ \\
\hline 190 & 380 & 625 & 1205 & 5.7 & 0.5 \\
\hline
\end{tabular}

The damaged concrete in the plastic hinge zone near the bottom of the piers was removed and the damaged region was finished by early-strength concrete with a compressive strength of $47.1 \mathrm{MPa}$. The surface of the piers was smoothed using a concrete grinding machine after the early-strength concrete was cured for 24 hours. A steel tube was jacketed to specimen $\mathrm{A}$ and fixed on the footing by a steel flange as shown in Figure 2. The anchored flange was used to install the steel tube on the damaged piers rather than improve the reinforcement effect. Self-compacting concrete with high fluidity was filled in the between of the pier and steel tube. The proportion for the mixtures of the concrete is shown in Table 2. Fine aggregate was coarse sand and the size of coarse aggregate was not more than $20 \mathrm{~mm}$. Specimens B and C were repaired by wrapping two layers of BFRP and CFRP sheets, respectively, along the whole length with fiber orientation in the circumferential direction and an overlap length of $50 \mathrm{~mm}$. Both the BFRP and CFRP sheets were saturated with mixed epoxy, and a coat of epoxy was applied to the surfaces of the specimens. Any air bubbles were squeezed out using a roller brush.

2.3. Experimental Setup. All specimens were tested using the same experimental setup, as shown in Figure 3. The axial compressive load was applied via a hydraulic jack which can be controlled with a calibrated pressure gauge. The axial load was $150 \mathrm{kN}$ and the axial load ratio was 0.2 . The lateral load was applied by an actuator supplied by MTS Systems Corporation with the capacity of $250 \mathrm{kN}$. Strain gauges were bonded on the tension and compression sides of the longitudinal steel bars and the surface of the repaired materials in the longitudinal direction. The lateral displacement of the piers was measured by one LVDT at the height of the horizontal actuator.

All specimens were subjected to plastic cyclic loading while carrying a constant axial load through the test. The loading process was shown in Figure 4. The lateral loading

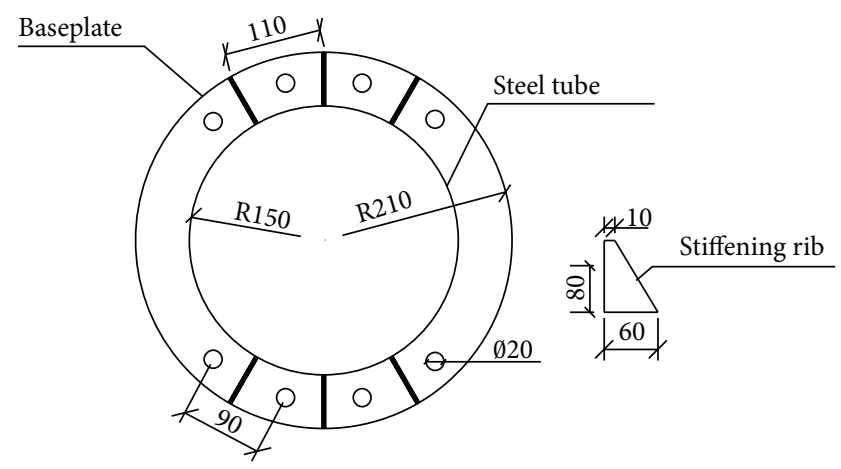

FIGURE 2: Details of the steel flange (unit: $\mathrm{mm}$ ).

cycles were controlled by lateral force or displacement increments. Firstly, all specimens were tested under force control, with a loading ratio of $0.5 \mathrm{kN} / \mathrm{s}$ and a load increment for each cycle of $5 \mathrm{kN}$. When the strain of the longitudinal steel bars recorded by the strain gauges reached the yield strain $1650 \times 10^{-6}$ after 4 cycles at a lateral force of $20 \mathrm{kN}$, the lateral displacement recorded by the LVDT at the height of the horizontal actuator was determined as the experimental yield lateral displacement $\Delta y$. The yielding loading occurred at a lateral force of $20 \mathrm{kN}$. The yielding displacements of the three original specimens A, B, and C are $28.36 \mathrm{~mm}, 27.09 \mathrm{~mm}$, and $26.65 \mathrm{~mm}$, respectively. The displacement control loading history for the original specimens included three complete cycles for $\Delta=1 \Delta y, 2 \Delta y, 3 \Delta y$, and $4 \Delta y$. The damage level of unreinforced specimens was $4 \Delta y$. The displacement control loading history for repaired specimens included three complete cycles for $\Delta=1 \Delta y, 2 \Delta y, 3 \Delta y$, and so on, until the shear capacity of the specimens declined to $85 \%$ of the peak load.

\subsection{Experimental Results and Discussions}

2.4.1. Failure Modes. Specimen A-R was observed in which the bottom of the steel tube yielded during $2 \Delta y$ cycles and the yield zone spread with the lateral displacement increasing. The cracks appeared on the surface of the footing during $4 \Delta y$ cycles and the cracks propagated with the lateral displacement increasing. Concrete spalling occurred at the footing and the yield zone in the steel tube increased during $5 \Delta y$ cycles. The shear capacity of the specimen decreased obviously during $6 \Delta y$ and the test was stopped.

Specimen B-R was observed in which two horizontal cracks appeared on the surface of the BFRP near $200 \mathrm{~mm}$ from the bottom of the pier during $2 \Delta y$ cycles. The crack appeared near the junction between the pier and the footing during $3 \Delta y$ cycles. The crack propagated with the lateral displacement increasing and the cracks in the BFRP cross the whole circle surface of the pier during $6 \Delta y$ cycles. The test was stopped during $7 \Delta y$ cycles.

Specimen C-R was observed in which horizontal cracks appeared at the bottom of the pier during $3 \Delta y$ cycles. A horizontal crack appeared on the surface of the CFRP during 

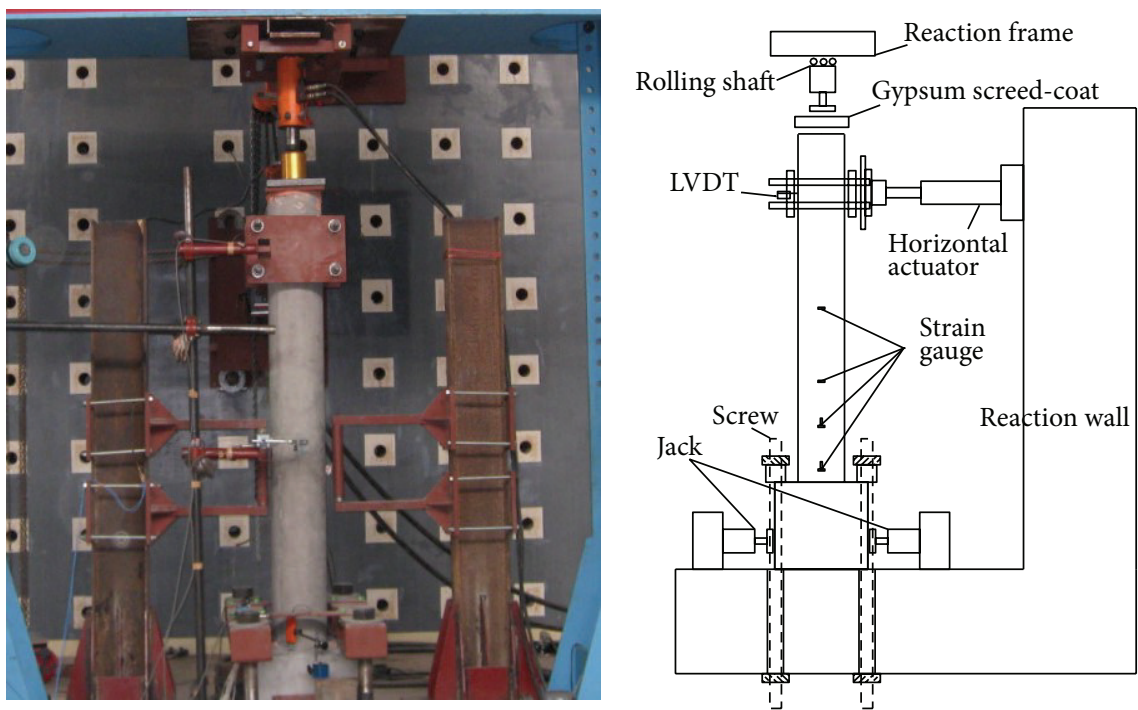

Figure 3: Testing setup.

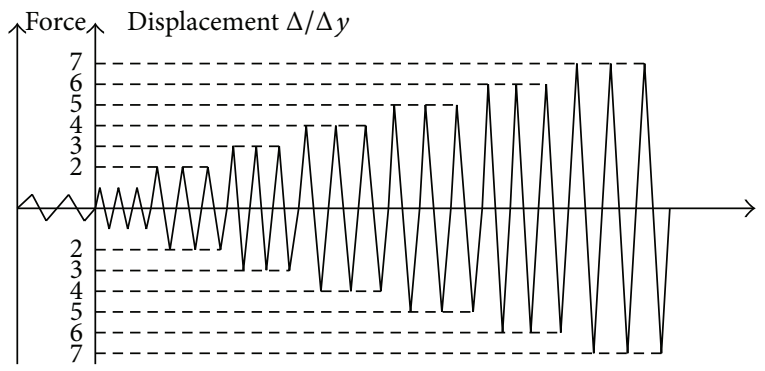

FIgure 4: Loading history.

$4 \Delta y$ cycles and the number of the cracks increased with the lateral displacement. The cracks in the CFRP crossed the whole circle surface of the pier during $6 \Delta y$ cycles. The test was stopped during $7 \Delta y$ cycles.

2.4.2. Hysteretic Curves. The original specimens have similar hysteretic behavior, as shown in Figure 6. The hysteretic curves of the original and repaired specimens are compared in Figures 7-9. Compared to the original specimens, the repaired specimens had larger ultimate displacements and stable changes in stiffness at later stages. In addition, more stable hysteretic loops with larger hysteretic loop area were found in Figure 7. All the original and repaired specimens have good plastic deformation capacity and energy dissipation, which indicated that all the three repair techniques can recover the seismic performance of the earthquakedamaged piers. Table 3 compares the energy parameters of all specimens. It shows that the steel tube repair increases the strength, ductility coefficient, and damage index [15] by $33.8 \%, 85 \%$, and $283 \%$, respectively, compared to the original piers. The strength index $I$, ductility coefficient $\mu_{\Delta}$ which had
TABLE 3: Comparisons of the energy parameters.

\begin{tabular}{lccccc}
\hline Specimen & Force $/ \mathrm{kN}$ & $\Delta_{1} / \mathrm{mm}$ & $\Delta_{u} / \mathrm{mm}$ & $\mu_{\Delta}$ & $W$ \\
\hline A & 37.0 & 28.36 & 56.79 & 2.0 & 30.13 \\
A-R & 49.6 & 21.05 & 77.56 & 3.7 & 115.51 \\
B & 31.9 & 27.09 & 66.26 & 2.4 & 39.39 \\
B-R & 39.8 & 31.59 & 105.36 & 3.4 & 90.87 \\
C & 32.2 & 26.65 & 71.64 & 2.7 & 31.11 \\
C-R & 32.4 & 26.26 & 112.95 & 4.3 & 83.37 \\
\hline
\end{tabular}

been used by Abela and Attard [16], and damage index $W$ can be expressed as

$$
\begin{aligned}
I & =\frac{F_{\max -r}-F_{\max }}{F_{\max }}, \\
\mu_{\Delta} & =\frac{\Delta_{u}}{\Delta_{1}} \\
W & =\frac{1}{F_{\max } \Delta_{1}} \sum_{i=1}^{n} w_{i}\left(\frac{K_{i}}{K_{1}}\right)\left(\frac{\Delta_{i}}{\Delta_{1}}\right)^{2},
\end{aligned}
$$

where $F_{\max }$ and $F_{\max -r}$ are the maximum bearing capacity of the original and repaired specimens, respectively, $\Delta_{1}$ is the yield displacement, $\Delta_{u}$ is the ultimate displacement, $w_{i}$ is the energy dissipated in the $i$ th cycles, $K_{i}$ is the secant stiffness in the $i$ th cycles, and $K_{1}$ is the idealized elastic lateral stiffness.

2.4.3. Skeleton Curves. The skeleton curves of the original and repaired specimens are compared in Figure 10. Specimen A- $R$ showed a significant improvement in the lateral stiffness and peak load when compared with the original specimen. Specimens B-R and C-R showed a similar behavior in 


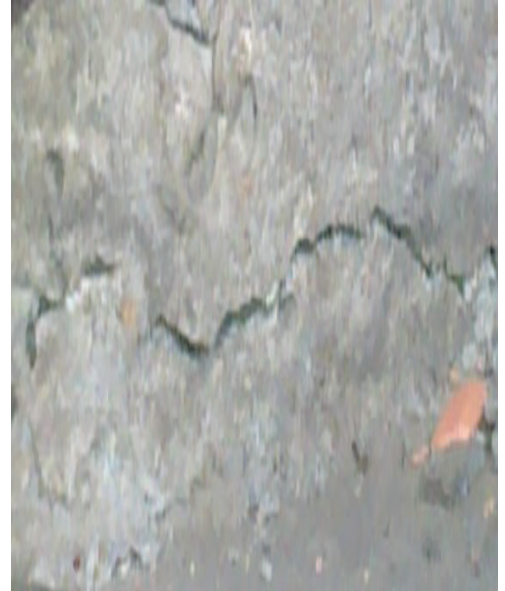

(a)

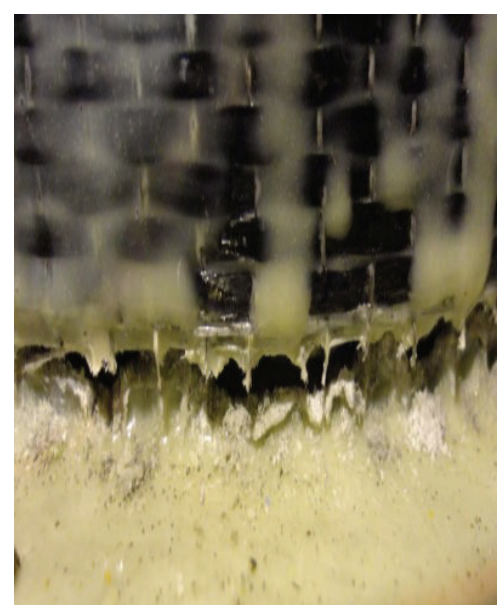

(c)

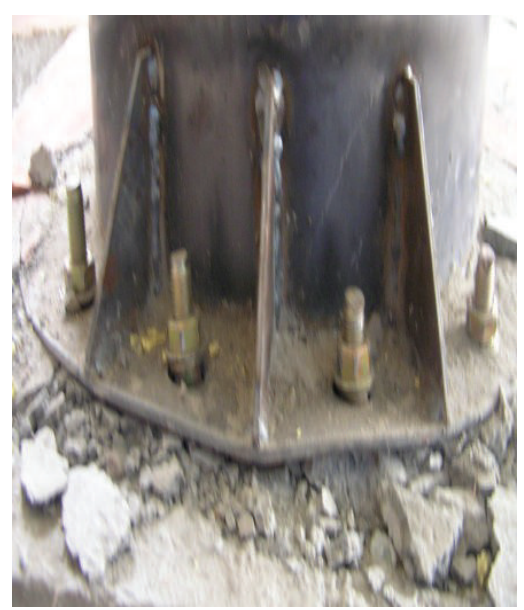

(b)

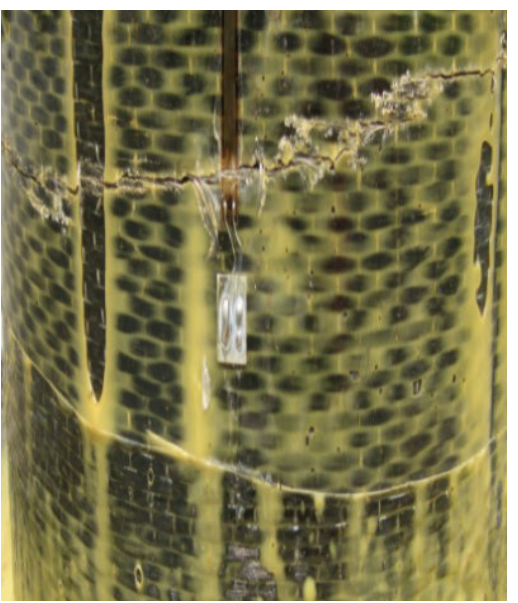

(d)

FIGURE 5: Failure modes of the specimens: (a) the original specimen; (b) specimen A-R; (c) specimen B-R; (d) specimen C-R.

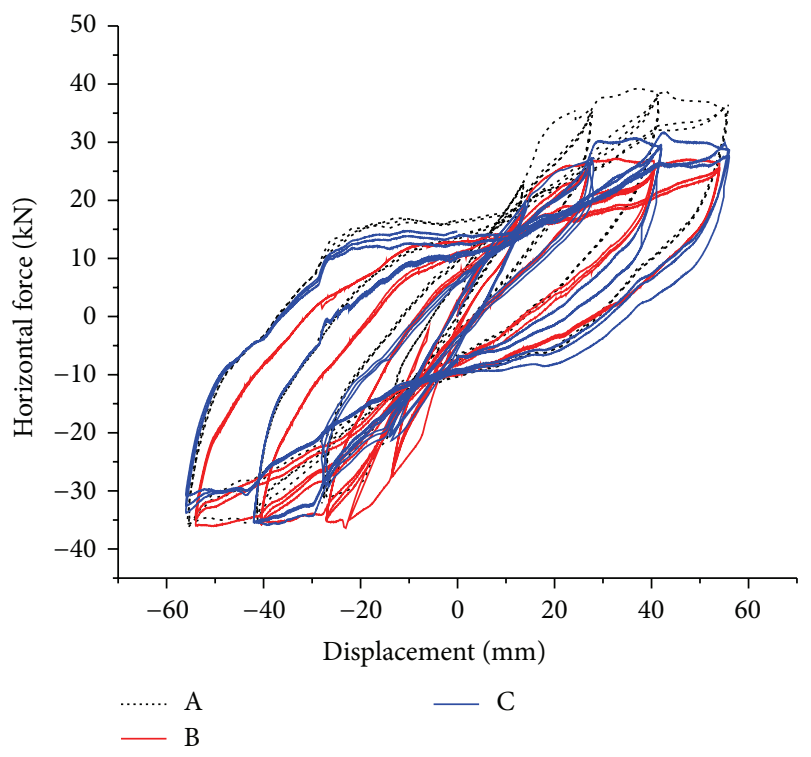

FIGURE 6: Comparisons of the hysteretic curves of original specimens.

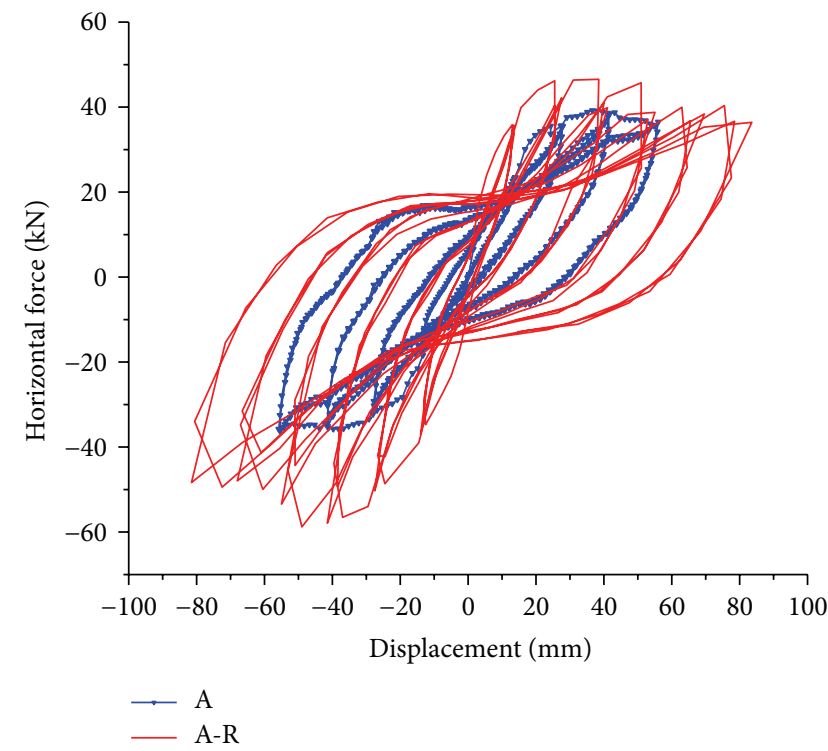

Figure 7: Comparisons of the hysteretic curves of specimens A and A-R. 


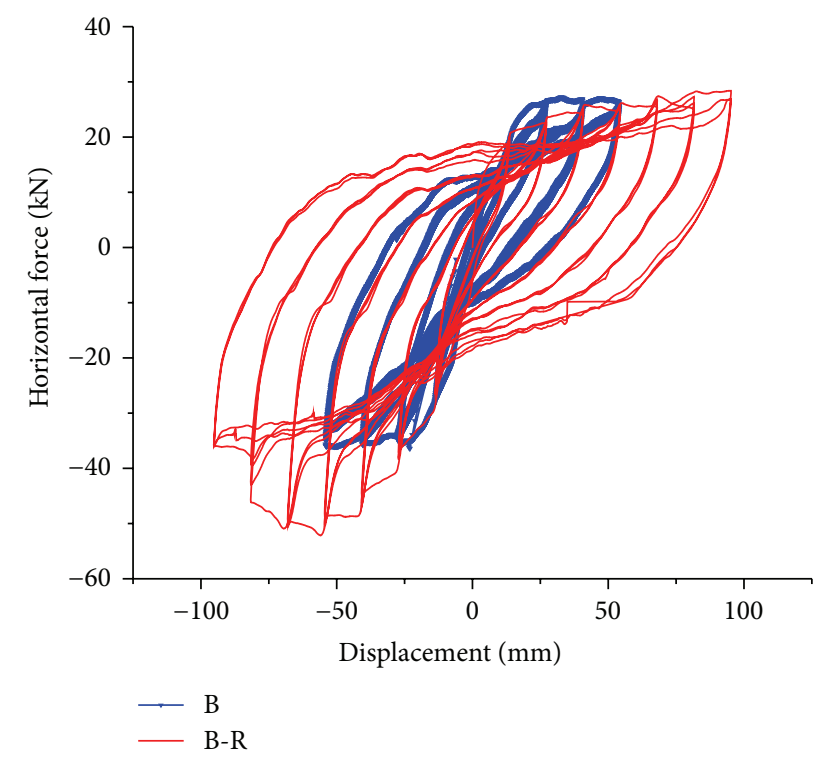

FIgURE 8: Comparisons of the hysteretic curves of specimens B and B-R.

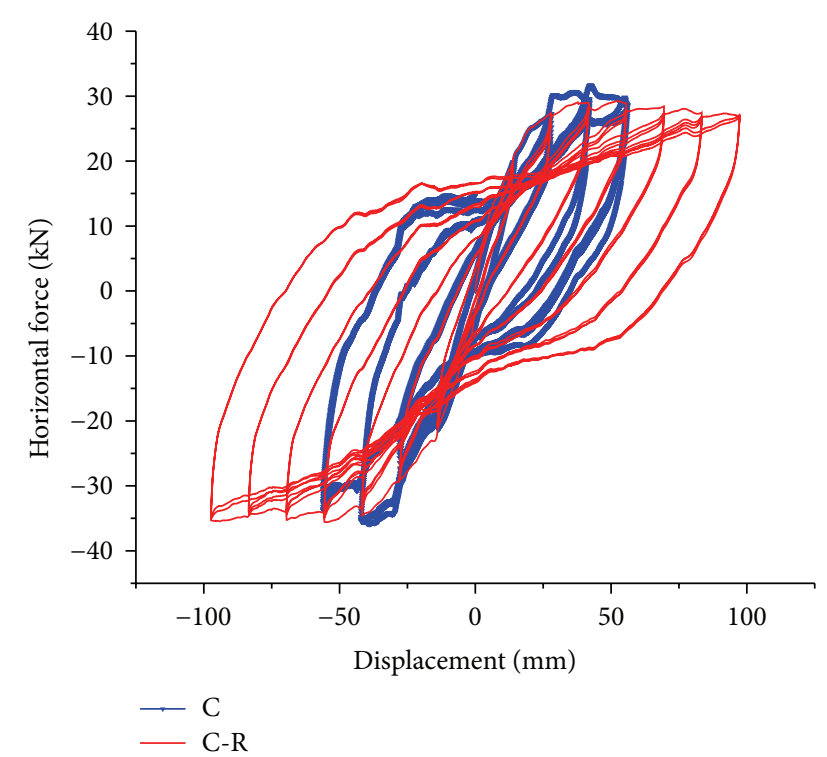

Figure 9: Comparisons of the hysteretic curves of specimens $C$ and C-R.

the lateral stiffness and peak load when compared with the original specimens. Therefore, the BFRP and CFRP sheet can only recover the seismic performance of the damaged pier.

\section{FE Analysis}

3.1. FE Models. The general purpose software package ANSYS was used. A nonlinear FE model was developed. The concrete is modeled with 8-noded Solid65 elements [17-20]. Solid45 elements were used for the steel plates at the support in order to avoid stress concentration of loading point. The steel tendons are modeled with one-dimensional elements LINK8. In order to avoid the termination of computing due to size effect, Shell43 element was used for steel tube. FRP jacket is modeled by linear elastic thick shell element Shell41 without bending strength. A perfect bond was assumed between the FRP jacket and the concrete by sharing the same nodes at the contact surface as recommended by previous FE studies [21, 22].

To account for the confinement effect, concrete is modeled with multilinear isotropic hardening (MISO). The compressive stress-strain curve based on concrete structure design code which defines the constitutive relationship of concrete under uniaxial compression [23] was shown in Figure 11(a). Stress-strain curves of longitudinal reinforcement and stirrup were shown in Figures 11(b) and 11(c). In addition, the William and Warnke five-parameter model was used as the failure criterion of concrete under multiaxial stress conditions, in which the failure surface is defined by at least two constants: the concrete ultimate uniaxial tensile strength, $f_{t}$, and the ultimate uniaxial compressive strength, $f_{c}$. Maximum tensile stress criterion (Rankine) is utilized to evaluate the concrete cracking. The failure will occur when the magnitude of the major principal stress of RC exceeds the value which caused fracture in a simple tension test; that is, concrete cracking and the tensile stress relaxation will occur when the stress reaches the maximum tensile stress. The shear transfer coefficients for open and closed cracks were 0.5 and 0.95 , respectively $[24,25]$, which had significant influence on the FEA results. Meanwhile, the multilinear kinematic hardening (BKIN) model for stressstrain relationship of the steel bar and the steel tube was adopted, as shown in Figure 11(d). CFRP and BFRP sheets are ideal elastic materials with a linear stress-strain relationship, as shown in Figure 11(e).

The column was modeled with the separate type finite element, which was a typical model with good bonding between concrete and steel bars. In addition, Solid65 and LINK8 are normally used to simulate concrete and steel bars in ANSYS, respectively. Concrete, steel bars, and tube were joined with common nodes [26]. The $15 \mathrm{~mm}$ concrete protective cover was not considered in the FE model to simplify calculation. Concrete columns and steel bars were modeled together. The birth-death element method was used to simulate the repair processing in FE. The elements of the steel tube, CFRP, or BFRP as death elements were not activated during the original piers damaged. After that, the elements of the repaired materials were activated to birth elements, and then the loading cycles applied to the piers were continued until failed. When the strain of the longitudinal steel bars reached the yield strain $1650 \times 10^{-6}$, the RC piers buckled in FE. This was the same as the experiment results.

3.2. FE Results and Discussions. The hysteretic curves between experimental results and FE results of the repaired piers are compared in Figure 12. As shown in the figure, agreement is good for the curves, which demonstrates that present $\mathrm{FE}$ analysis is accurate. The similar comparisons can be obtained for the FRP repaired piers. The strength of the damaged 


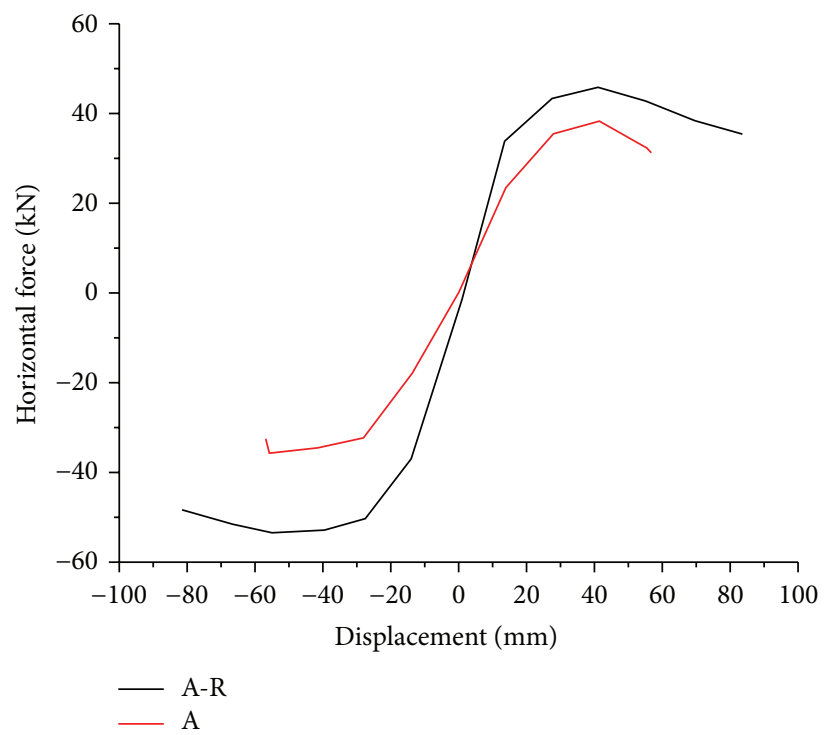

(a)

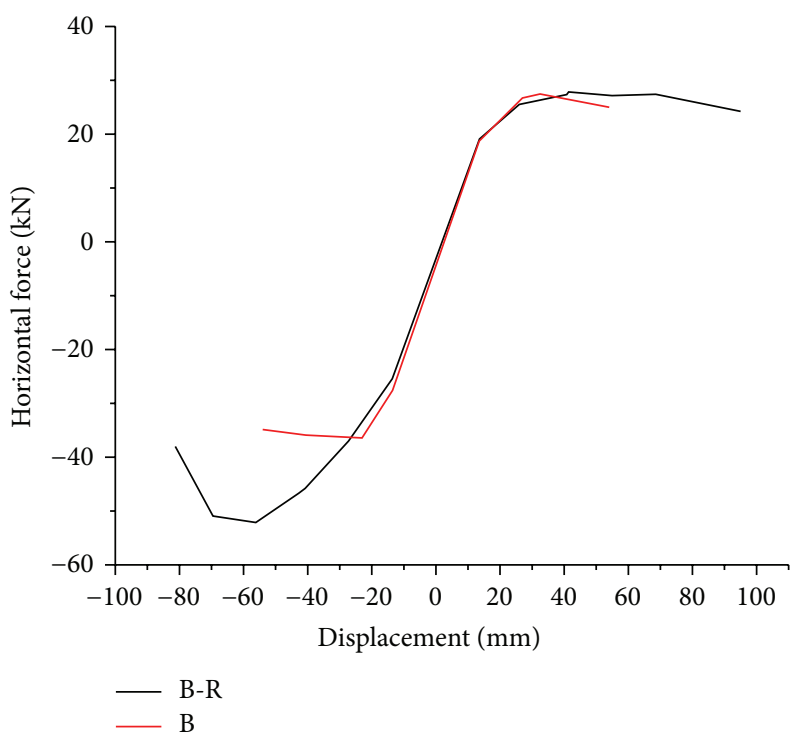

(b)

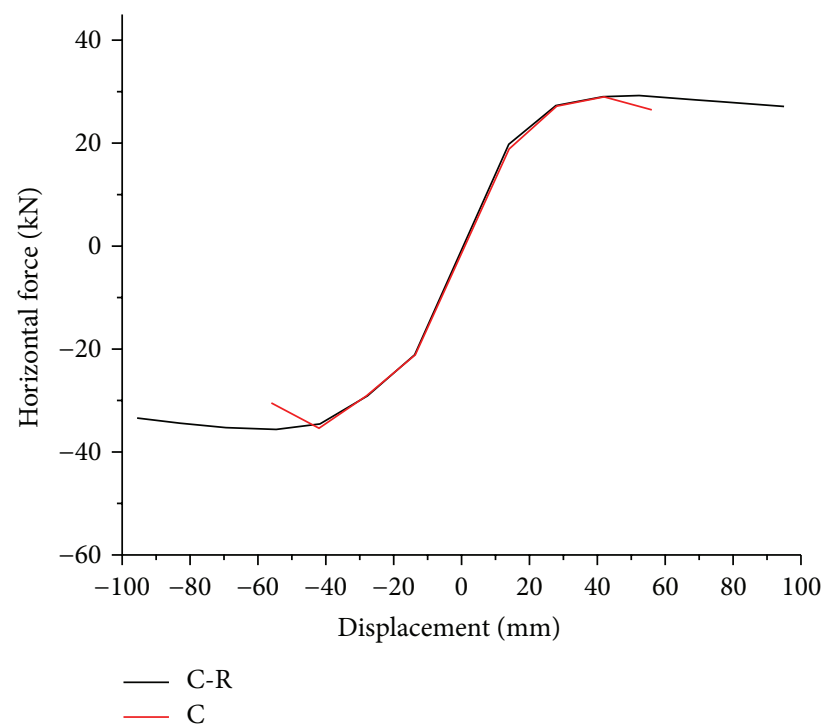

(c)

Figure 10: (a) Comparison of the specimen A skeleton curves. (b) Comparison of the specimen B skeleton curves. (c) Comparison of the specimen $\mathrm{C}$ skeleton curves.

bridge pier repaired with BFRP or CFRP increased marginally, which is in agreement with the experimental results. The hysteresis curve and skeleton curves are shown in Figures 13 and 14. Figure 13 showed that the hysteretic curves of the specimen repaired with the steel jack had larger areas compared to others. It indicated the hysteresis curve of steel tube repaired pier is full and approximately spindleshaped. Comparing with other repaired piers and the original pier, steel tube repaired pier has better plastic deformation capacity, seismic behavior, and energy dissipation capacity. As shown in Figure 14, the steel tube repairing significantly improves the lateral stiffness and peak load, while the FRPs repairing has only marginal improvement due to their thin thickness. The FE results shown in Figures 13 and 14 are similar to those obtained from tests. Finite element analysis results showed that the steel tube repaired pier had a $60.6 \%$ and $61.1 \%$ increase in the initial stiffness and strength, respectively, compared to the original piers.

The range of steel jacket buckling in compressive area increased gradually, and the repaired pier failed when the longitudinal reinforcement yielded ultimately. After failure the pier has obvious deformation, but crushing in concrete element is not significant due to the steel jacket confinement. The strength and ductility increased by FRP wrapping in this paper are not obvious. It is because of the different design criterion, concrete deterioration, and thin thickness of FRP 


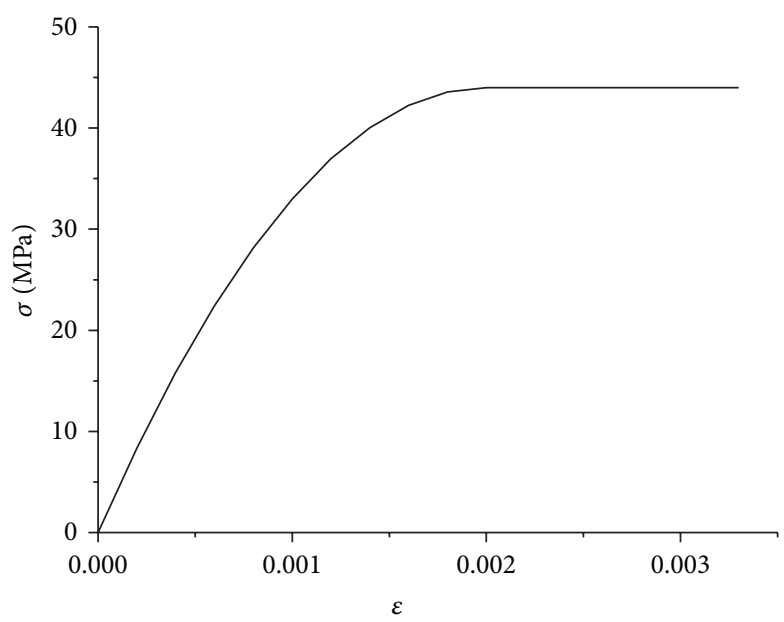

(a)

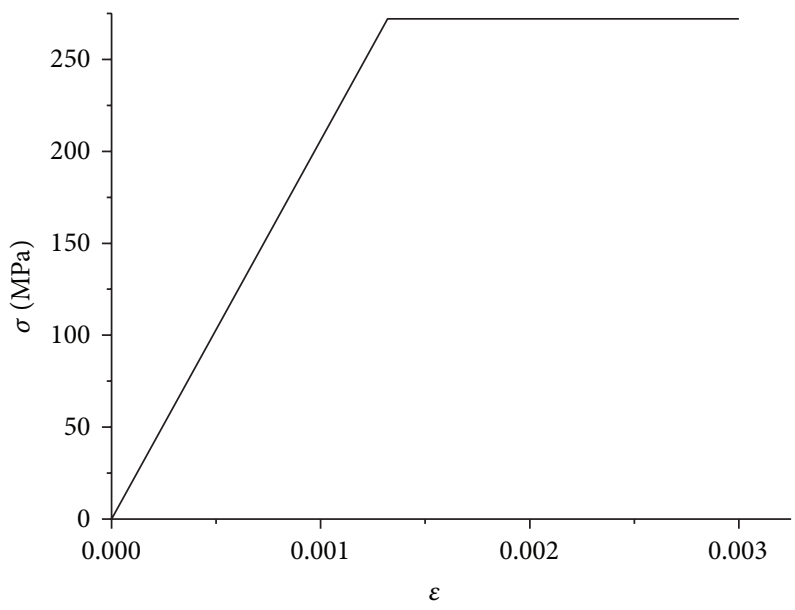

(c)

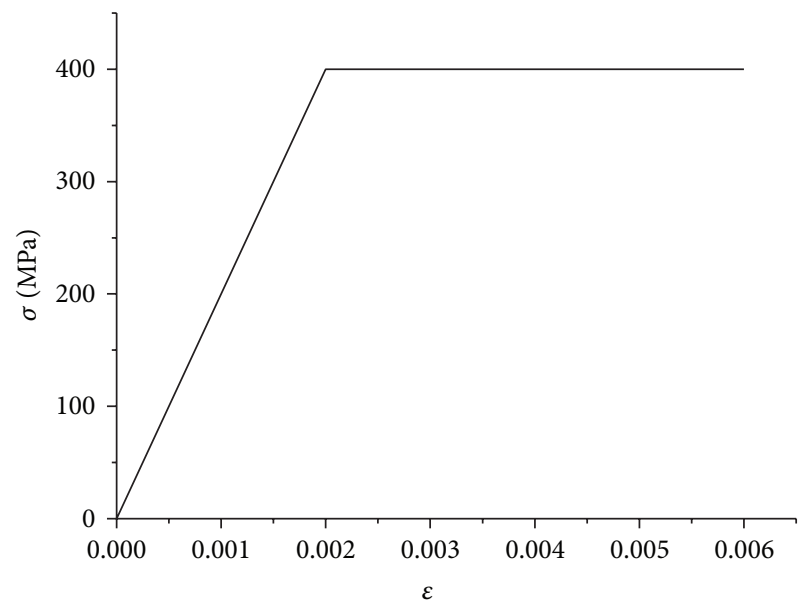

(b)

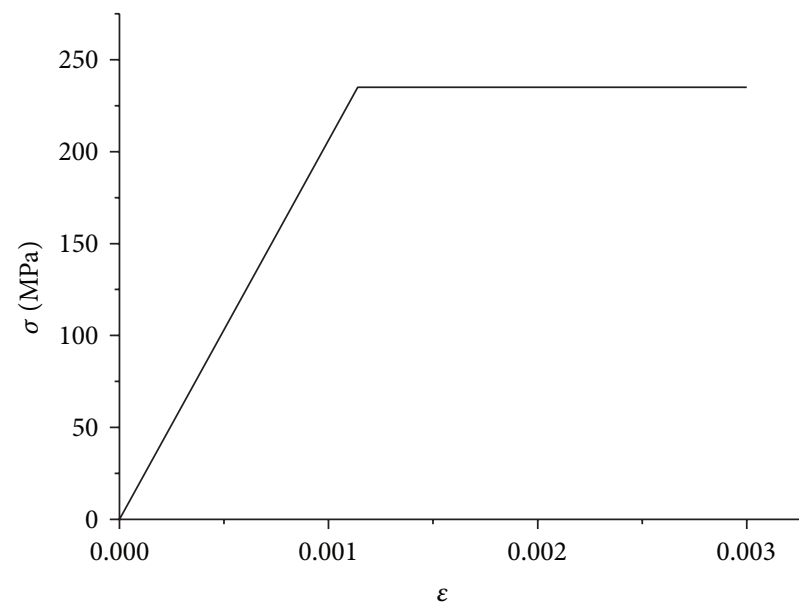

(d)

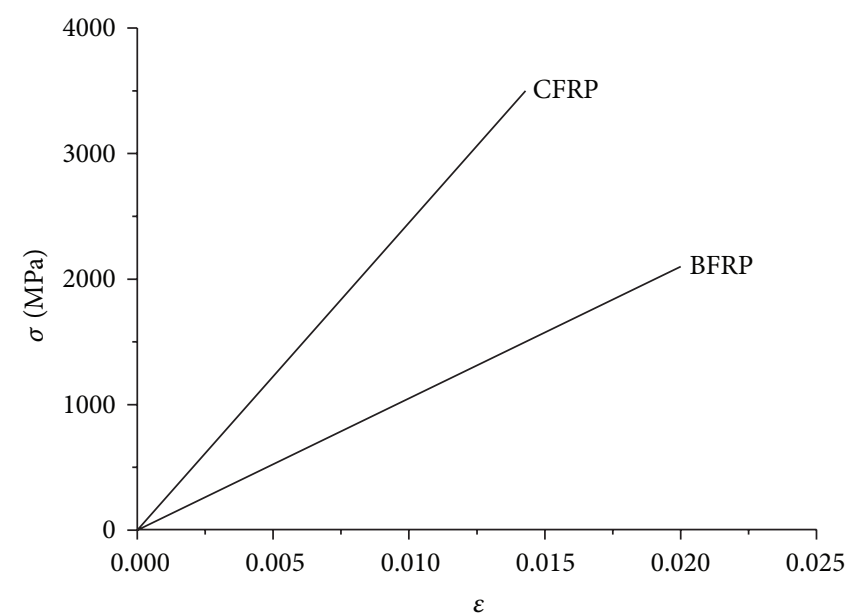

(e)

FIGURE 11: Stress-strain curve of materials: (a) concrete; (b) longitudinal reinforcement; (c) stirrup reinforcement; (d) steel tube; (e) FRP. 


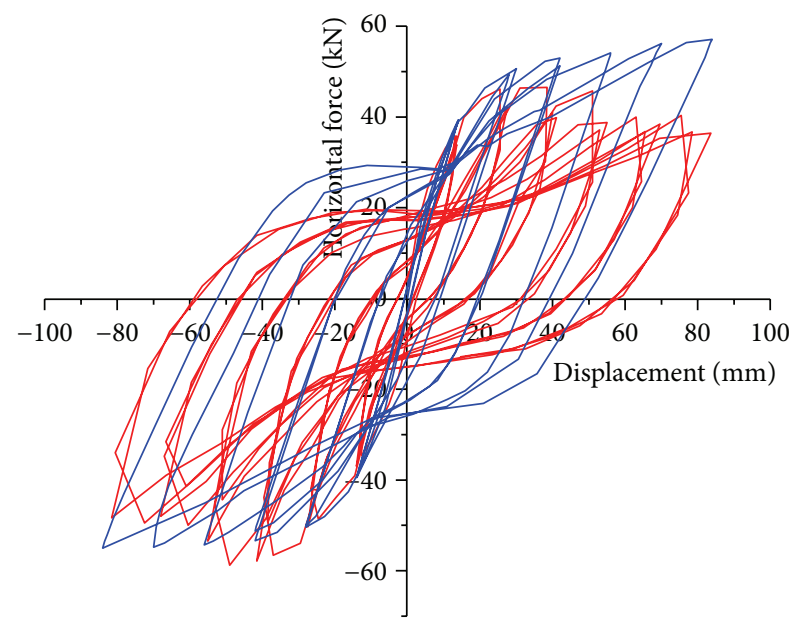

FE results
Experimental results

FIGURE 12: Comparison of the hysteretic curves between experimental results and FE results of the steel tube repaired pier.

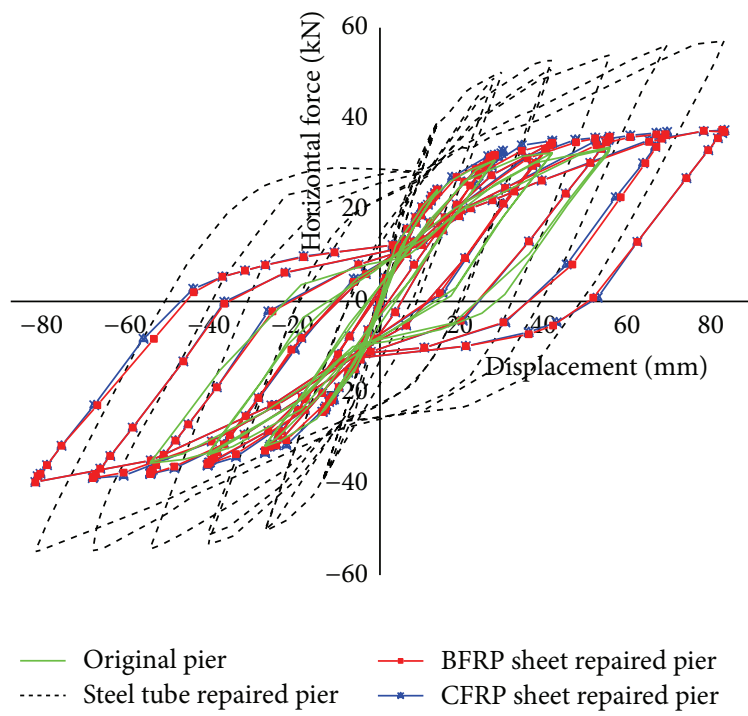

FIgURE 13: Comparisons of the hysteretic curves obtained from FE analysis.

sheets. Figures 13 and 14 showed that the enhancement of the lateral stiffness by FRP wrapping was limited in comparison with steel tube jacketing. The experimental results in literatures $[27,28]$ showed that the hysteresis curve of FRP confined concrete columns shows obvious phenomenon of pinch effect and poor ductility, which is in accord with the FE results in this study.

\section{Conclusions}

In this paper, experimental and FE studies were conducted to investigate confinement effectiveness of different materials

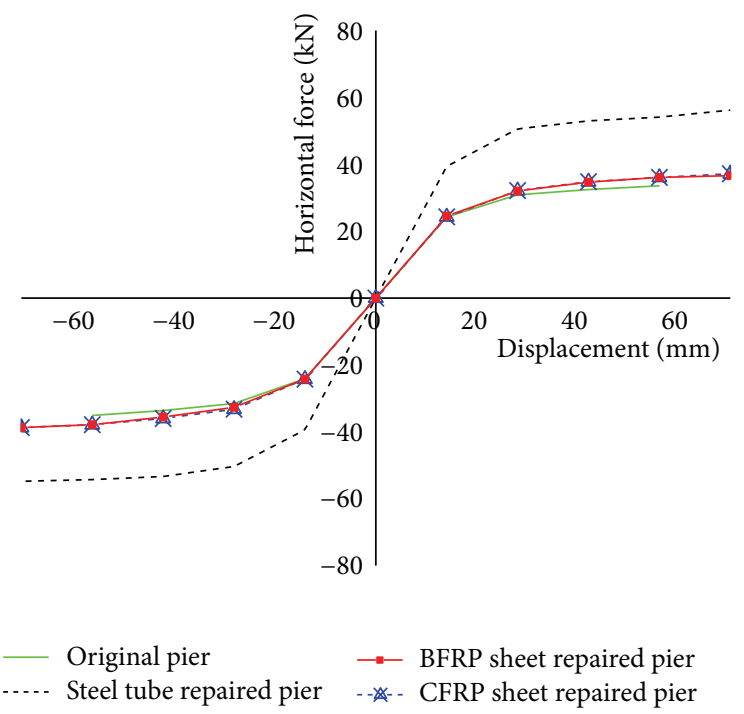

FIGURE 14: Comparisons of the skeletons obtained from FE analysis.

and techniques in retrofitting circular earthquake-damaged concrete bridge piers. Three 1/5 scale piers were predamaged by pseudo-static cyclic loading and repaired by steel tube, BFRP, and CFRP sheets, respectively. The repaired piers were tested by pseudo-static cyclic loading to fail. The experimental and FE results showed that the repaired piers had similar hysteretic curves with the original specimens and all the three repair techniques can recover the seismic performance of the earthquake-damaged piers. Steel tube jacketing can significantly improve the lateral stiffness and peak load of the damaged pier, while the BFRP and CFRP sheets wrapping cannot improve these properties due to their thin thickness. Experimental results showed that the steel tube repair increased the strength, ductility coefficient, and damage index by $33.8 \%, 85 \%$, and $283 \%$, respectively, compared to the original piers. Finite element analysis results showed that the steel tube repaired pier had a $60.6 \%$ and $61.1 \%$ increase in the initial stiffness and strength, respectively. In addition, FRP sheet wrapping was a more attractive technique for the cases where there was severe access confinement or associated high costs with installation time.

\section{Conflict of Interests}

The authors declare that there is no conflict of interests regarding the publication of this paper.

\section{Acknowledgments}

This work is supported by the National Natural Science Foundation of China through Grant 51278131, Program for New Century Excellent Talents in University through Grant NCET-13-0739, and Fok Ying Tong Education Foundation through Grant 131073. 


\section{References}

[1] A. Brown and M. S. Saiidi, "Investigation of effect of nearfault motions on substandard bridge structures," Earthquake Engineering and Engineering Vibration, vol. 10, no. 1, pp. 1-11, 2011.

[2] H. Han, X. L. Du, J. B. Liu, Z. X. Li, L. Y. Li, and J. F. Zhao, "Seismic damage of highway bridges during the 2008 Wenchuan earthquake," Earthquake Engineering and Engineering Vibration, vol. 8, no. 2, pp. 263-273, 2009.

[3] K.-S. Youm, H.-E. Lee, and S. Choi, "Seismic performance of repaired RC columns," Magazine of Concrete Research, vol. 58, no. 5, pp. 267-276, 2006.

[4] X. Cao, Y. Wei, G. F. Li, G. Wu, and Z. S. Wu, "Research on the reinforcement and the repair techniques for RC bridge piers," Construction Technology, vol. 40, pp. 60-64, 2011.

[5] Y. H. Chai, M. J. N. Priestley, and F. Seible, "Seismic retrofit of circular bridge columns for enhanced flexural performance," Structural Journal, vol. 88, no. 5, pp. 572-584, 1991.

[6] N. Matsumoto, Y. Kitago, and T. Sato, "Restoration, seismic strengthening and seismic design for railway viaducts after Hyogoken-Nanbu earthquake," Cement and Concrete Composites, vol. 22, no. 1, pp. 47-57, 2000.

[7] D.-S. Gu, G. Wu, Z.-S. Wu, and Y.-F. Wu, "Confinement effectiveness of FRP in retrofitting circular concrete columns under simulated seismic load," Journal of Composites for Construction, vol. 14, no. 5, pp. 531-540, 2010.

[8] Z. Sun, D. Wang, X. Du, and B. Si, "Rapid repair of severely earthquake-damaged bridge piers with flexural-shear failure mode," Earthquake Engineering and Engineering Vibration, vol. 10, no. 4, pp. 553-567, 2011.

[9] D. H. Lee, J. Park, K. Lee, and B. H. Kim, "Nonlinear seismic assessment for the post-repair response of RC bridge piers," Composites Part B: Engineering, vol. 42, no. 5, pp. 1318-1329, 2011.

[10] X. Wang, Z. Wu, G. Wu, H. Zhu, and F. Zen, "Enhancement of basalt FRP by hybridization for long-span cable-stayed bridge," Composites Part B: Engineering, vol. 44, no. 1, pp. 184-192, 2013.

[11] M. Zhang, G. Wu, Y. M. Jiang, Y. Tian, and X. Q. Hu, "Experimental research on mechanical properties of basalt fber reinforced composites," Hi-Tech Fiber \& Application, vol. 32, pp. 1521, 2007.

[12] Degin Code for Strengthening Concrete Structure, China Building Industry Press, Beijing, China, 2006.

[13] F. Seible, M. J. N. Priestley, G. A. Hegender, and D. Innamorato, "Seismic retrofit of RC columns with continuous carbon fiber jackets," Journal of Composites for Construction, vol. 1, no. 2, pp. 52-62, 1997.

[14] S. Rocca, N. Galati, and A. Nanni, "Large-size reinforced concrete columns strengthened with carbon FRP: validation of existing design guidelines," in Proceedings of the 3rd International Conference on FRP Composites in Civil Engineering (CICE '06), Miami, Fla, USA, December 2006.

[15] Z.-G. Sun, B.-J. Si, D.-S. Wang, X. Guo, and D.-H. Yu, "Research on the seismic performance of high-strength concrete columns with high-strength stirrups," Engineering Mechanics, vol. 27, no. 5, pp. 128-136, 2010.

[16] C. M. Abela and T. L. Attard, "Analytical models and guidelines for the ductility enhancement of circular reinforced concrete single-column bents using fiber-reinforced polymers," Journal of Bridge Engineering, vol. 16, no. 1, pp. 171-176, 2011.
[17] E. Erduran and A. Yakut, "Drift based damage functions for reinforced concrete columns," Computers \& Structures, vol. 82, no. 2-3, pp. 121-130, 2004.

[18] L. D. Huang and H. Li, "Seismic analysis of shear wall with energy dissipation components by using nonlinear finite element method," Journal of Wuhan University of Technology, vol. 36, pp. 1456-1459, 2004.

[19] L. Wang, T.-C. Wang, and J.-W. Qi, "Experimental and theoretical study on hysteretic behavior of concrete-filled rectangular steel tubular frame," Journal of Tianjin University, vol. 38, no. 1, pp. 41-46, 2005.

[20] Y. R. Li, J. Shen, and T. Qiu, "Seismic behaviors of transferring joints for steel reinforced concrete beam," Journal of Zhejiang University, vol. 40, no. 1, pp. 96-102, 2006.

[21] H. M. Elsanadedy, Y. A. Al-Salloum, S. H. Alsayed, and R. A. Iqbal, "Experimental and numerical investigation of size effects in FRP-wrapped concrete columns," Construction and Building Materials, vol. 29, pp. 56-72, 2012.

[22] O. Youssf, M. A. ElGawady, J. E. Mills, and X. Ma, "Finite element modelling and dilation of FRP-confined concrete columns," Engineering Structures, vol. 79, pp. 70-85, 2014.

[23] B.-J. Si, Z.-G. Sun, D.-S. Wang, and Q.-X. Wang, "Modeling methods on simulation of hysteretic behavior of bridge piers based on ANSYS software," Journal of Wuhan University of Technology, vol. 29, no. 6, pp. 76-79, 2007.

[24] K. Damian, M. Thomas, and Y. Solomon, "Finite element modeling of reinforced concrete structures strengthened with FRP laminates," Report for Oregon Department of Transportation, Oregon Department of Transportation, Salem, Ore, USA, 2001.

[25] B.-J. Si, Z.-G. Sun, X.-D. Ren, and D.-S. Wang, "Finite element analysis of the hysteretic behavior of RC bridge piers," Journal of Wuhan University of Technology, vol. 41, pp. 105-109, 2009.

[26] S.-Y. Chang, Y.-F. Li, and C.-H. Loh, "Experimental study of seismic behaviors of as-built and carbon fiber reinforced plastics repaired reinforced concrete bridge columns," Journal of Bridge Engineering, vol. 9, no. 4, pp. 391-402, 2004.

[27] Q. Yu, Z. Tao, and X. Gao, "Several problems in seismic behavior of FRP-confined concrete columns," Earthquake Engineering and Engineering, vol. 26, pp. 75-82, 2006.

[28] X. Gao, Z. Tao, Y. F. Yang et al., "Hysteretic of circular RC columns confined with FRP jackets," Industrial Construction, vol. 35, pp. 11-14, 2005. 

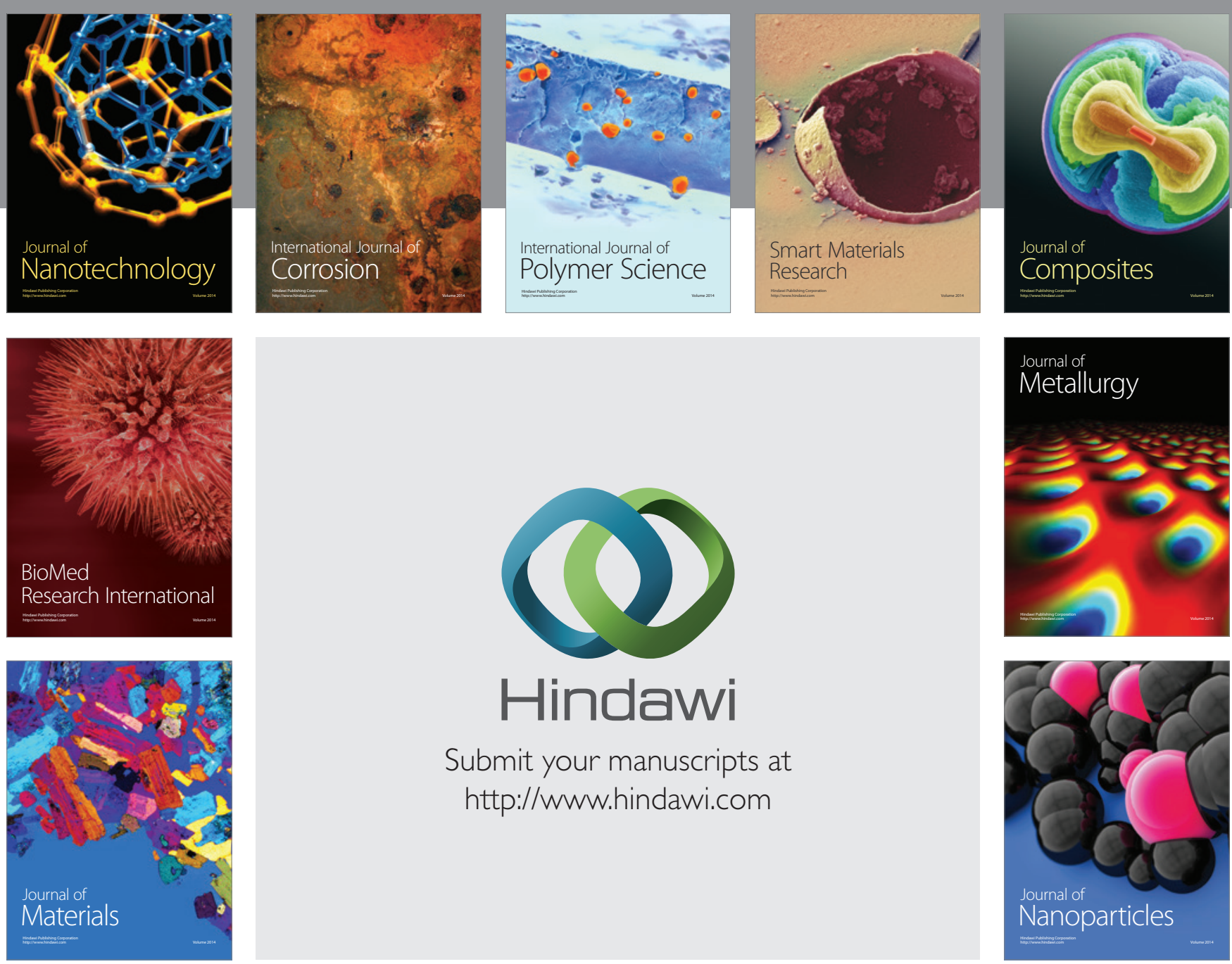

Submit your manuscripts at http://www.hindawi.com
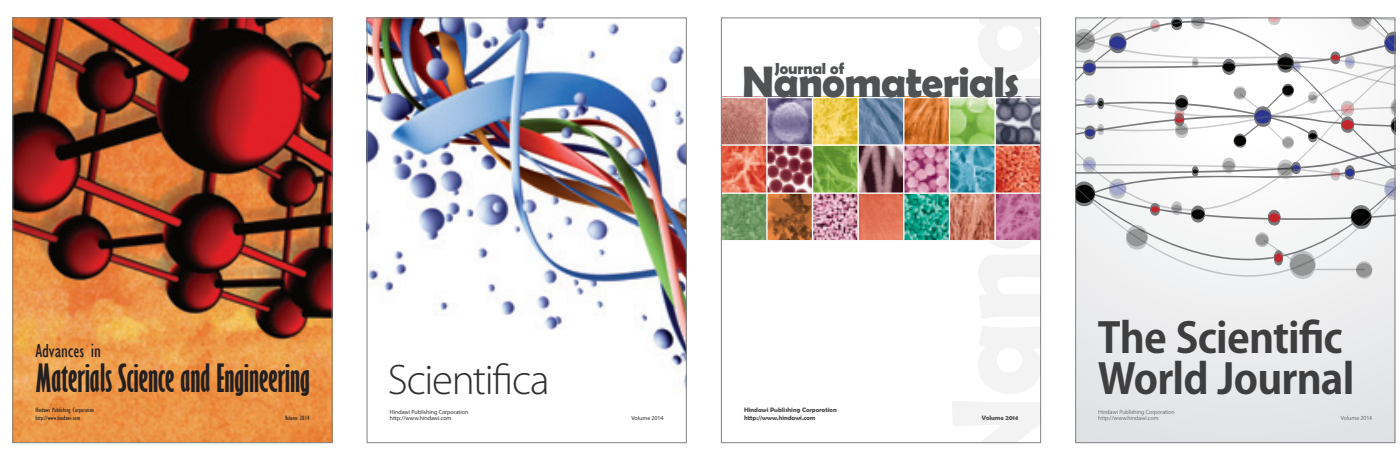

\section{The Scientific World Journal}
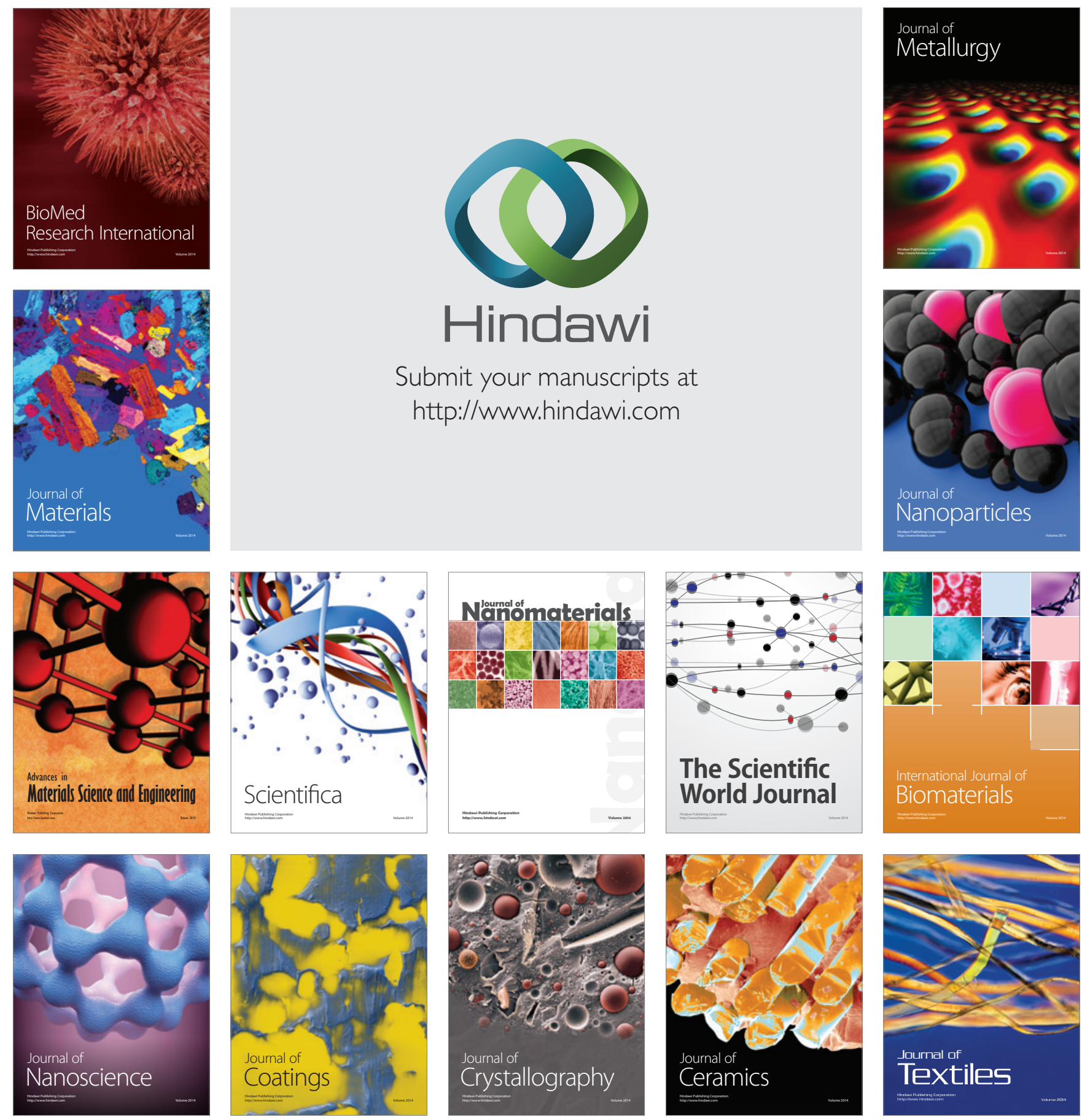